
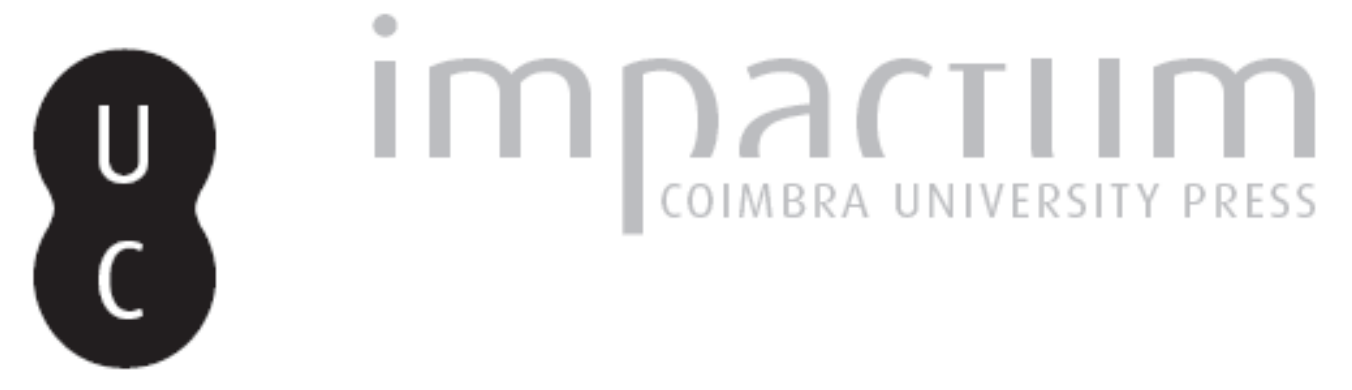

\title{
[Recensão a] Environnement et Marché Intérieur
}

\author{
Autor(es): $\quad$ Sadeleer, Nicolas de \\ Publicado por: CEDOUA \\ URL \\ persistente: \\ URI:http://hdl.handle.net/10316.2/37564 \\ DOI: \\ DOI:http://dx.doi.org/10.14195/2182-2387_24_6
}

Accessed : $\quad$ 26-Apr-2023 14:16:35

A navegação consulta e descarregamento dos títulos inseridos nas Bibliotecas Digitais UC Digitalis, UC Pombalina e UC Impactum, pressupõem a aceitação plena e sem reservas dos Termos e Condições de Uso destas Bibliotecas Digitais, disponíveis em https://digitalis.uc.pt/pt-pt/termos.

Conforme exposto nos referidos Termos e Condições de Uso, o descarregamento de títulos de acesso restrito requer uma licença válida de autorização devendo o utilizador aceder ao(s) documento(s) a partir de um endereço de IP da instituição detentora da supramencionada licença.

Ao utilizador é apenas permitido o descarregamento para uso pessoal, pelo que o emprego do(s) título(s) descarregado(s) para outro fim, designadamente comercial, carece de autorização do respetivo autor ou editor da obra.

Na medida em que todas as obras da UC Digitalis se encontram protegidas pelo Código do Direito de Autor e Direitos Conexos e demais legislação aplicável, toda a cópia, parcial ou total, deste documento, nos casos em que é legalmente admitida, deverá conter ou fazer-se acompanhar por este aviso.

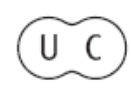




\section{RevGEDOUA}

N.224_Ano XII_ 2.09

> Doutrina

Gestāo Integrada da Zona Costeira Portuguesa

Fernanda do Carmo

E um dia a Falésia veio Abaixo. Pisco de Erosāo da Orla Costeira, Prevenção e Hesponsabilizaçāo

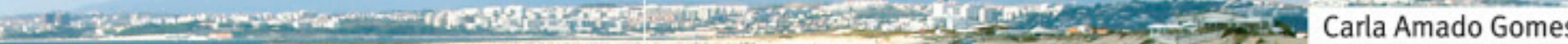

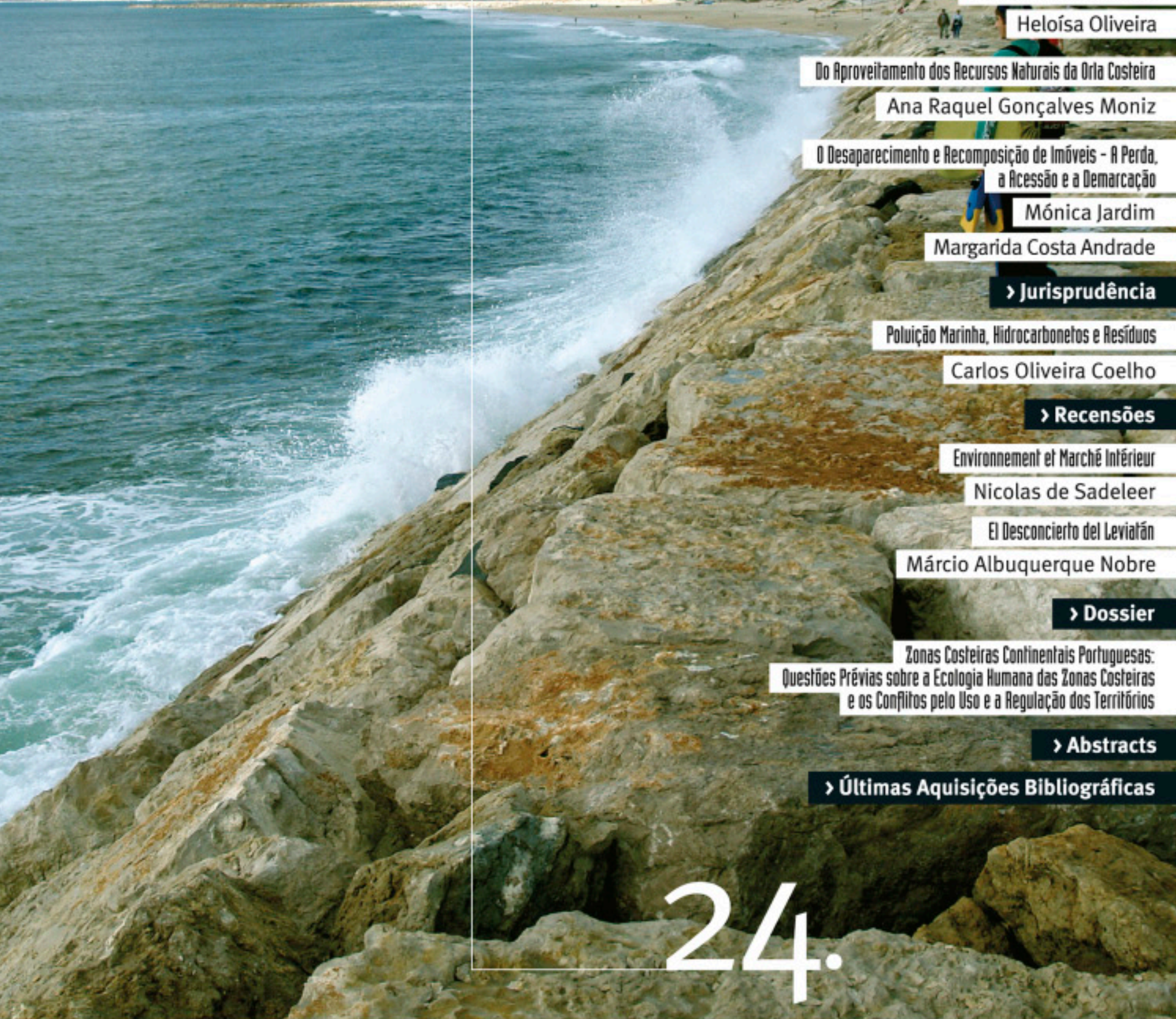




\section{Environnement et Marché Intérieur, Nicolas de Sadeleer, \\ Collection Commentaire J. Mégret, Université de Bruxelles, 2010, 584 paginas}

Na colecção de referência de Direito Europeu, o Comentário Mégret, foi publicado mais um tratado, desta vez sobre Ambiente e Mercado Interno.

Ninguém escapa à crise ambiental. No período de quatro décadas, a União Europeia muito contribuiu para o boom do Direito do Ambiente e para a integração das preocupações ambientais nas outras políticas públicas. Os direitos nacionais são tributários das escolhas normativas da União Europeia. Desde há algum tempo que as normas de produtos, os objectivos de qualidade ecológica e as restrições energéticas são uma realidade tangível, tanto para as empresas como para os poderes públicos.

Ora, em virtude do carácter evolutivo dos problemas ecológicos e da consideração crescente da incerteza nos processos de decisão, este direito não pára de se complexificar, ramificar e interagir com outras áreas do direito da União. À primeira vista, este quadro regulamentar parece impenetrável.

No intuito de facilitar a compreensão dos princípios e noções fundamentais, em torno das quais se articula esta disciplina jurídica, o procede-se, na primeira parte, a uma análise sistemática e crítica das obrigações que decorrem do direito primário da União.

As relações entre as disposições relativas ao ambiente e os outros artigos dos Tratados, nomeadamente os relativos ao mercado interno, à saúde, ao consumo e à agricultura, são sistematicamente postos em destaque. Os mecanismos institucionais próprios desta política são igualmente analisados.

Em virtude das numerosas reformas que foram levadas a cabo durante a anterior legislatura, o direito derivado encontra-se num ponto de viragem. Uma multiplicidade de instrumentos jurídicos, no âmbito das políticas agrícola, da pesca, dos transportes, da energia, do mercado interno ou do comércio externo, começaram a integrar recentemente as novas preocupações ambientais.

A segunda parte do comentário oferece aos leitores uma radioscopia, através de numerosos quadros, dos diferentes aspectos do direito derivado. A luta contra as alterações climáticas, a política de produtos, bem como o âmbito da protecção jurisdicional, são objecto de uma análise aprofundada, integrando os últimos desenvolvimentos normativos e jurisprudenciais.

Após esta apresentação global, a terceira e quarta partes tratam, de forma exaustiva, dos conflitos que opõem as medidas nacionais de protecção do ambiente ao direito do mercado interno e ao direito da concorrência. A compatibilidade das medidas de restrição às trocas comerciais, o respeito pelos regimes de notificação técnica, a admissibilidade de acordos ou associações de empresas, as posições dominantes, os serviços de interesse económico geral e os auxílios de Estado são objecto de um exame crítico pela bitola da jurisprudência e da prática da Comissão Europeia. 


\section{RerCED光UA}

> Recensão

Sobre estas diferentes problemáticas, o comentário faz o ponto da situação sobre o estado do direito aplicável, incluindo os contributos da jurisprudência, mas também propõe pistas de conciliação entre as dimensões económica e ambiental.

Não dirigido apenas a especialistas, este comentário visa tornar acessível uma matéria densa e evolutiva a um público mais vasto de aplicadores do direito.

Nicolas de Sadeleer, Facultés Universitaires Saint-Louis, Bruxelas 